\title{
PIECING TOGETHER: BODY CONTROL, MUTABILITY AND ENTERTAINMENT TECHNOLOGY IN INFINITE JEST
}

\author{
ANA CHAPMAN \\ Universidad de Málaga \\ achapman@uma.es
}

Received 29 July 2019

Accepted 24 November 2019

KEYWORDS: Infinite Jest; David Foster Wallace; body representation; entertainment; addiction; external manipulation

PALABRAS CLAVES: Infinite Jest; David Foster Wallace; representación del cuerpo; entretenimiento; adicción; manipulación externa

\section{ABSTRACT}

The aim of this essay is to explore body representation and its significance in David Foster Wallace's novel Infinite Jest (1996). By doing so, it will correlate (ab)use and domination of entertainment to the description of the particular corporeality present in the novel, which is portrayed as being malleable, disconnected, machine-like and monstrous. Although published in the late 90s, the novel anticipated most accurately how entertainment would be consumed in contemporary times and its possible effects on individuals. Thereby, this essay analyzes how the body is shaped in Infinite Jest through the use of a current neuropsychological perspective and contemporary theories of the self as an attempt to reflect upon Wallace's description of the body and its relation to the world of entertainment.

\section{RESUMEN}

El objetivo de este trabajo es explorar la representación del cuerpo y su significado en la novela de David Foster Wallace, Infinite Jest (1996). Para ello, se relacionará el (ab)uso y dominación del entretenimiento con la descripción de la propia corporalidad presente en la novela, en la que se representa dúctil, inconexa, mecánica y monstruosa. Aun siendo publicado a finales de los 90, la novela anticipa con gran exactitud cómo el entretenimiento iba a ser consumido en tiempos contemporáneos, así como sus posibles efectos en el individuo. Por este motivo, el presente ensayo analiza cómo el cuerpo es moldeado en Infinite Jest a través del uso de perspectivas neuropsicológicas y de teorias actuales sobre la 
identidad, en un intento de reflexionar sobre los usos que Wallace hace de la descripción del cuerpo y su relación con el mundo del entretenimiento.

\section{INTRODUCTION}

This paper presents a new insight of David Foster Wallace's Infinite Jest (1996) by incorporating philosophical and neuropsychological theories of the body and mind (including Tsakiris 2010; Longo and Haggard 2010) to reveal what lies behind the emphasis on body parts and its external extensions in the novel. Moreover, most of the literature reviews on this narrative deal with body per se such as the anomalous, prosthetic representation (Russell 2010), the text in itself, a body narrative construction (Burn 2003, 2013; Cioffi 2000) or irony (Goerlandt 2006; Bartlett 2016). It has also been discussed in relation to the term entertainment (Sayers 2012), the use of entertainment, the media and corporate power over choice, its addiction and effects on subjectivity (Boswell 2003; Freudenthal 2010; Hayles 1999) among others.

This work aims to expose what seems to underline Wallace's criticism and foretelling of the (ab)use of contemporary technology and entertainment and its impact on self and particularly the body. The contemporary body tends to be engaged in a corporeality dualism that loiters in a broad scope of studies and inside the framework of corporeality modeling. The current state of biological and cultural connections has brought a two-edged and therefore ambiguous, paradoxical and even cryptic view of the body. Its instability and its outcome of multiple perceptions portrays a certain futuristic body molding pattern in Infinite Jest.

The body renders a new set of ideas and depictions which convert it into a vehicle for many areas of human enquiry. Thus, by enforcing a multiple fragmented corporeality construction it divergently creates a less uniform being and species. Consequently, the corporeal becomes an entity of disconnected parts where the different sections of the whole become more applicably conceived for different purposes.

Body parts are detached in the way Deleuze and Guattari define as fractals, "aggregates whose number of dimensions is fractional rather than whole, or else with continuous variations" (534). There is a sense of "indetermanence" of the body, that is, 
Piecing Together: Body Control, Mutability and Entertainment Technology in Infinite Jest

"cultural indeterminacy" combined with "technological immanence" (Hassan 153). However, the body still gathers within itself a naturalness of biological ground. It has become a commoditized site for the cultural, scientific and technological fields whereby the corporeality becomes an open system that is exposed to changes from the outer world. The individual becomes a non-linear chaotic system where its parts are molded but still entail some bioconnection. It analogically adopts "the illusions of substantial unity" (Foucault, "Nietzsche, Genealogy and History" 83), it becomes a sort of bricolage, as if it had been assembled taking parts from different pieces of furniture that never seem to coincide to perfection.

Abnormal representations that are found in the novel parallel the new notion and experience with innovations in science and technology which unsettle the basis of the natural body. Therefore, these monstrous recollections and the emphasis on parts seem to be on the borderline of social reality and fiction on the one hand, and on the other, recreations, apprehensions and lived experience. The blurred boundary between science-fiction and social reality, according to Donna Haraway, is "an optical illusion" (149). Hence, it accentuates that bodies in Infinite Jest are true representations of the corporeality stance. The surreal bodies are embraced in the realm of lived experiences. As Haraway states "any objects or persons can be reasonably thought of in terms of disassembly; "no natural" architectures" (162). The use of these portrayals engages in what she defines as being at stake "in the Western's sense, the end of man" (162) or at least the disconcertment and anxiety which has been triggered by the particular events. The common definition of man undergoes a new scrutiny where there seems to sprout less of a biological description than a fragmented and multiple source from its basis.

There are countless examples in Infinite Jest where the body's focal point is given to separate limbs rather than to the body as a whole. From the very beginning of the novel the reader catches glimpses of an account of body limbs withdrawn from a corporeal totality. However, this does not entail the idea of complete body disconnection due to the fact that parts still belong to (but are not utterly possessed by) a single character. There is still unmistakably a feeling of an uncontrolled mutable wholeness. Body parts are portrayed as autonomous or with certain independency of action from mind. Therefore, characters fall into a description of being an 
assemblage of parts, as machinery with different sections of independent movement and action results.

Characters are a lopsided collection of parts far from being a coherent and unitary entity. On the very first page, Hal Incandenza identifies the people on the board as not being complete, akin to nonunited bodies, as if he were "surrounded by heads and bodies" (Wallace 3). There is a clear intentionality on Wallace's part from an early stage in Infinite Jest for readers to become aware of this dismembering process of the body. It strikes readers in the very first sentence, as what they encounter is an unusual description of lived experience. Not to mention that the depiction of bodies lacking integrity is not only reflected upon bodies without concise harmony of their limbs but also upon characters with non-belonging parts arranged in the same body.

Characters fall under the dialectic of separate limbs which implies a challenge to portray the body under the classical concept of the natural. There is a wide range of characters who have enhanced some corporeal zone of themselves (e.g. Enfield Tennis Academy's tennis players) and others who have some kind of deformity (e.g. as if not part of the whole). For instance, the psychologist that treats Hal Incandenza after his father's death has hands that "were no bigger than a four-year-old girl's" (257). Hal goes on to describe them as:

surreal. This massive authoritative figure, with huge red meaty face and thick walrus moustache and dewlaps and a neck that spilled over the rim of his shirt-collar, and his hands were tiny and pink and hairless and butt-soft, delicate as shells. The hands were the capper. (257)

The center of interest lying on distinct parts is apparent when the reader first encounters one of Orin Incandenza's "Subjects", a Swiss hand-model (565). Wallace consciously focuses on limbs to produce this autonomous and disconnected sense of corporeality. There is no further description given of the hand-model in terms of her general physique and readers only acknowledge that the subject has beautiful hands. Furthermore, at Enfield Tennis Academy there are many examples of the latter, such as "anachronistic Wilson" (110). During Wilson's performance, his body is engaged in a mere description of his limbs as the focus on body parts becomes more prominent by means of a simulation of slow-motion tennis captures $(112-17)$. It recognizably accentuates tennis players as been ruled by 
Piecing Together: Body Control, Mutability and Entertainment Technology in Infinite Jest

the "machine-language of the muscles" (118). The following exemplifying section is a clear instance of what a natural body comes to be after iterative motions in the tennis world:

No wasted motion, egoless strokes, no flourishes or tics or excesses of wrist. Over and over, each forehand melting into the next, a loop, it's hypnotizing, it's supposed to be. You're supposed to pretend it's you $[. .$.$] with the fluid and egoless strokes. (110, emphasis added)$

By the use of the word "egoless," it is made explicit how the corporeality in the novel is somewhat amiss. In fact, egoless implies that there is no distinct separation of what one would consider his or her body and the external world.

This major emphasis on parts entails different means. To some extent, it stresses parts as the result or effect of mechanical actions which mainly occurs at Enfield as limbs call for a targetoriented performance. They present exaggerated forms as a "tendency towards unequal distribution and "jagged seams"” (Russell 149). Tennis players lose their character as it is shifted towards what seems to be a loophole in individuality. They become discontinuous and unattached limbs transforming into autonomous entities (as independent of action from the whole). The enhancement in this case of the arm is the axiom for tennis players' lives, "[s]o most of the E.T.A. classic look of bodies hastily assembled from different bodies' parts, especially when you throw in the heavily muscled legs and usually shallow chests and the two arms of different sizes" (Wallace 100). In other cases, the focus lies on malformations hinting at another type of abuse (drugs). The subjectivity of parts allows body sections to gain a major role and place over the self and the individual in the narrative. Moreover, this separation demonstrates a chaotic external domination and instruction over them as a linked corporeality site.

\section{MONSTROUS AND UNCONTROLLED BODY PARTS}

Wallace's narrative neglects the portrayal of characters' general physical appearance and personality to prominently give way to corporeality parts. Spatial connection does not strike the reader as being a major achievement. The foremost interest lies in limbs and the exhaustion of them, both as entertainment forms (social performance and drug entertainment). James Incandenza or Himself 
takes a step further in one of his cartridges where the emphasis is on a single part which eventually takes over the complete body. In Cage III-Free Show bodies become shaped into massive eyeballs; "spectators watch performers undergo unspeakable degradations so grotesquely compelling that the spectators' eyes become larger and larger until the spectators themselves are transformed into gigantic eyeballs" (988). The exhaustion of one part of the body transforms it into enhanced representations. Provocatively, it implies that spectators submit themselves to this form of entertainment advertently. They willingly drop their conscious control over their body to give way to the exaltation of one separate part of their corporeality whereby giving prominence to the limb that can be a transmission vehicle for generated entertainment.

This feature of disconnectedness of limbs hints at a sort of "monstrosity" as an inherent state of the body. It reminds the reader of a Frankensteinian body produced by the merging of biology and science, culture and technology. There is no former knowledge of the origins of this new body and consequently no control over its parts. It is an idea that appears in the novel with characters that have been configured into an assembly of various monstrous pieces. No explicit conception of how bodies have arrived at this point is given in the novel, which permits and then forces the reader to attempt to discover the reason for this type of body formations. The novel makes no effort to show the reader why there has been this loss of origins and why the body is as it stands inside the pages of Infinite Jest.

Since the body has lost its core natural representation of body functions as an assemblage of several formations and origins, this has enforced on its description a sort of non-human, thus monstrous construction. By using the term monstrosity, it refers not only to something non-human or of a mutant animalistic creature but of being of a different size or volume than the rest of the physical entity, transforming this body to post/subhuman forms. For example, the "sweat guru" Lyle at Enfield Tennis Academy, who had "saucers of muscle protrude from him and run together so that he looks almost crustacean" (127). Pat Montesian, the Ennet house executive director and ex-addict's "right arm had atrophied into a kind of semi-claw" (465). Don Gately, a former drug addict who is a current counselor in residence at Ennet is described as being "the size of a young dinosaur, with a massive and almost perfect square head" (55) which points perhaps at a Frankenstein type. On a digital entertainment cartridge directed by the Incandenza's middle-born 
Piecing Together: Body Control, Mutability and Entertainment Technology in Infinite Jest

child Mario and narrated by his youngest brother Hal, Tennis and the Feral Prodigy (note the description of the prodigy as an untamed one), Hal illustrates a tennis routine as to "squeeze the tennis ball month after year until [it looks] like a gorilla's arm or a stevedore's arm pasted on the body of a child" (173). The limb is depicted as a "wild beast's" one which does not correlate to the main body of a young tennis player. Wallace gives way to the debate over the dubious established boundaries and connections of the body, an idea that is heightened in Haraway's words that no real research has "convincingly separated humans from animals" (152). A line clearly blurred and at stake in Infinite Jest where the human is not only difficult to distinguish from animals but also from monstrosities (originated from different regimes).

Upon describing Mario Incandenza's birth, he is identified in terms of a monstrous mutant formation; "he had to be more or less scraped out, Mario, like the meat of an oyster from a womb to whose sides he'd been found spiderishly clinging, tiny and unobtrusive, attached by cords of sinew at both feet and a hand, the other fist struck to his face by the same material" (Wallace 313). Mario Incandenza suffers from an innumerous array of diseases that have disfigured him. For example, he suffers "Volkmann's contracture's some kind of severe serpentine deformation of the arms following a fracture that hadn't been set right [...]; bradyauxesis refers to some part(s) of the body not growing as fast as the other parts of the body" (119) but the list unrelentingly expands and moves on to describe how Mario's teeth "are bicuspids and identical [...] like a porpoise" (119). Mario's portrayal becomes the apex of a monstrous or deformity construction/formation in the novel.

\section{BODY PARTS AT ENFIELD TENNIS ACADEMY}

Within the two main worlds portrayed in the novel where this dissembling takes place, a new turn towards body representation rises. Among the tennis players at Enfield, body parts in isolation seem to be represented in an idealized Greek form of perfection. Procedures entailing this outcome are through the exhaustion of the limbs whereby it enhances the limbs towards brutal and monstrous perfection. In consequence, it decentralizes or diminishes the rest of the body. Again, the relevance of the body is pointed at the limb that can produce social entertainment. 
Inside the sport world, body parts become individualized as if they were of a separate nature thence haloed. Orin Incandenza's leg falls into a deified perspective. When describing him as a football player, the focus is on "The Leg" (as it is referred to in the novel). His overused leg becomes a separate entity which seems to have little resemblance or connection to Orin as a whole. It becomes the center of his being; "his oversized left arm and big left leg remain at rest at all times in the morning" (Wallace 43). In Mario's puppet show that is shown on "11/8, Continental Interdependence Day" (380), Gentle attends a match where Orin is playing. Though he attempts to remember the punter's name, no name is given only " $t]$ his one slim cat with an outsized leg and slightly less outsized arm. Never saw punts I could hear before" (439). In another instance, Orin is instructed to jump with fake wings at the stadium and due to his fear of heights he does not pray for his whole but "please Lord, spare the Leg" (66). By virtue of Wallace's descriptions, the implication is revealed that it is the reader who has to focus on the limbs. By doing so, the reader achieves a position where he/she is forced to fall into a process of searching for an understanding.

One of Hal's close friends, Ortho "The Darkness" Stice, is described as an assembly of body parts:

One of those athletes whose body you know is an unearned divine gift because its conjunction with his face is so incongruous. He resembles a poorly spliced photo, some superhuman cardboard persona with a hole for your human face. A beautiful sports body, lithe and tapered and sleekly muscled, smooth -like a Polycleitos body, Hermes or Theseus before his trials- on whose graceful neck sits the face of a ravaged Winston Churchill. (636)

Disassembled bodies entail forms of anti-biological representation (perhaps emphasizing the message behind) of lived bodies that will never reach completion. They become the guise of an external ground of performance (in this case some form of entertainment). These examples of unnatural formations that are "aesthetically challenged" (18) or disproportional, enhance the creation of a state of nonwholeness. It is to some extent Nietzsche's view on body as not being a single unity but a plurality of (sometimes conflicting) drives (Couzens 11). Wallace seems to be paralleling it to a real-life disconnection where lived bodies may not only entail an underlying sense of separate and disconnected members but also that they will 
Piecing Together: Body Control, Mutability and Entertainment Technology in Infinite Jest

never attain wholeness in a multiple-driven world of experience. By the non-ending attempts, characters are stuck in a limbo of incompleteness with the need to reach the opposite stance. This lack of wholeness drags them into performing repetitive unconscious acts as an apparent outside way to reach completeness.

Although Enfield tennis players are described as owning some divinity, this characteristic is not permanent: "It is an evanescent state to [infinitely] work on" (Russell 150). The continuous drilling originated from an external element that imposes itself and consequently weakens the line between body and the external influence. This dismantling of the notion of unitary bodies provides a connection to Matthew R. Longo's main research on body representation from a neuroscientific stance. His investigations show why it may be surprising or abnormal for readers to encounter this kind of character. The use of them seems to be a way for Wallace to try to make readers become aware of this human perception of body. In this particular research, M.R. Longo together with Patrick Haggard reach the conclusion that "we experience our body as a coherent, volumetric object [while in contrast] the brain [also] appears to maintain highly fragmented representations of individual body parts and skin surfaces" (9). The latter creates a sense of analogy which is reflected in Infinite Jest as well as emphasizing Wallace's glimpse at what may be one of the problems in representing and living in a corporeal site of conflicting drives.

\section{HUMAN MACHINES AND DISCONNECTED AGENCY}

It appears that science-fiction logic runs the conception of bodies in a way that supports particularly Longo's results. The fragmented bodies are engaged in non-ending attempts to reach completeness that is admittedly unreachable, and which precipitates them into becoming automatic machines. Therefore, following what David Porush points out in discussing the corporeal site, humans are the "Soft Machine" (1984) not only for their body construction but for the body's dismembered and mechanical parts. Characters senselessly follow their environment rules which foreground the separation of limbs whilst making less distinct the bounding line between corporeality and the external. In a technological driven society (as seen in the novel), we have become cybernauts, which is to some extent an overextended development of us in the form of machines. Haraway points out that currently, "we are not sure 
[about the distinction between] natural bodies and machines [...] Our machines are disturbingly lively, and we ourselves frighteningly inert" (152). Representing the body as mechanically driven raises the question of where agency is positioned within the human body and self. Can bodies be part mechanical and also have thinking sides? Furthermore, as Nisbett and Wilson in "Telling More than We Can Know: Verbal Reports on Mental Processes" have observed, the occurrence of a mental process does not guarantee the individual any special knowledge of the mechanism of this process: "Instead, the person seeking personal self-insight must employ a priori causal theories to account for his or her own psychological operations" (Wegner 67).

According to Ian Hacking, there has been a shift "in the last twenty-five years, to a "neo-Cartesian" mode of objectifying the body through mechanistic knowledge of its parts, including the brain, as separate from the mind and "self"" (Freudenthal 193). The material part becomes separated from the self, whilst leaving the latter to be at a loss in the external controlled body it lives in. As Hacking notes, "we view our body parts - including our brains - as machinelike, controllable in a neo-Cartesian light" (193). This can be extrapolated to Enfield Tennis Academy whereby the external entity of the body is enclosed into a mechanical control. This is underpinned by the idea of how characters apparently do not think why they have to do it but indulge the commands arranged for them (reinforced in the drilling style occurring at Enfield). At Ennet House Drug and Alcohol Recovery House, they are not supposed to think why or how the addiction may disappear but to follow rules without questions. For instance, Don Gately would mechanically pray in the mornings without thinking who or what he was praying to. He indulged in bodily rituals whilst waiting for the acceptance of the exercises to finally overcome the problem, in this case the addiction. But by mechanical repetition, Gately is stuck in the belief that there is some deeper explanation for the former ritual. Contrasting his views, Hal seems to have indulged in and is aware of what mechanical rituals stand for in their lives as tennis players:

[t]he machine-language. The autonomical part that makes you breath and sweat. It's no accident they say to you Eat, Sleep, Breathe tennis here. These are autonomical. Accretive means accumulating through sheer mindless repeated motions. The machine-language of the muscles. Until you can do it without 
Piecing Together: Body Control, Mutability and Entertainment Technology in Infinite Jest

thinking about it, play [...] Forget about is there a point, of course there's no point. The point of repetition is there is no point. Wait until it soaks into the hardware and then see the way this frees up your head. A whole shitload of head-space you don't need for the mechanics anymore, after they've sunk in. Now the mechanics are wired in. Hardwired in. (Wallace 117-118)

By reinforcing this working out, the mind seems to have become a "mental armor" (118), shielded by the machine or unprotected of experience and the external (as it has no personal involvement in it). The self does not possess anything and is the one controlled by the mechanical actions and that is why it has no experience of agency.

It is what Foucault defines as the docile body, "one that may be subjected, used, transformed, and improved, and that [...] can only be achieved through strict regimen of disciplinary acts" (Discipline and Punish 136). Foucault argues that we are utterly controlled by society's technology of power. In this case one area in the novel is controlled by the social power of entertainment. Tennis players become absolute products for the entertainment of others; they become mechanized for the recreation of others. That is why it might be stated that "arms and legs are full of numb imperatives" (Bourdieu 69) in the sport world. In discussing body in a natural form, Bourdieu points out that although those imperatives seem perfectly natural, they are embodied in political mythology. According to his own words, "bodily hexis is political mythology realized, embodied, turned into a permanent disposition" (Bourdieu 69-70). Tennis players as well as Orin Incandenza in the football arena are installed and formed by external whims. Tennis players are defined as "Going Through The Motions [and who are wired] into the motherboard" (Wallace 118). Motherboard here makes direct reference to what may be considered the maze of the external sociological power for the pursuit of entertainment and pleasure. Their bodies are controlled by the "power" of social entertainment. The body is not theirs but to be exploited by others. So, the "mental armor" (118) is in fact left unprotected, inexperienced and has nothing to cling onto as its own belonging.

Thus, for instance, Hal Incandenza and other tennis players in the novel are created and transformed by the social input which creates a fictional body. They are told to endure a mechanical process by squeezing "the tennis ball rhythmically month after year until [they] feel it no more than [their] heart squeezing blood" 
(Wallace 173). Characters are half mechanical, as Hal expresses it at the very beginning of the novel: "my chest bumps like a dryer with shoes in it" (5). This whole idea of humans as hybrids of technology is observable in many passages in Infinite Jest and it presents itself immersed within a conflict about the border between machine and the self. Joelle, for example, is described while walking as machinelike, "her legs on autopilot, she a perceptual engine" (221).

Focusing on mind matters, there is a noticeable intention of controlling the mind and the self with mechanical actions in order for them to react in an automated way responding to commands. Mario's Tennis and the Feral Prodigy is structured in the form of a manual as there are many sections where Hal starts with "here is how" (173). In this script, Hal seems to outline the norms required to become one of those whom he defines as being at the top of the tennis championship, "just grim machines à la John Wayne" (438); a machine, wired into the social reality network. Hal establishes those steps as a way to enable the detachment of consciousness from the drills that tennis players need. He recollects from his own personal manual that, "here is how to avoid thinking about any of this by practicing and playing until everything runs on autopilot and talent's unconscious exercise becomes a way to escape yourself, a long waking dream of pure play" (173). He even lists how to do bodily actions as he is aware of the external force and the self-struggle to overcome this; "here is how to sweat" (174). He continues defining it; "this is your body. They want you to know. You will have it with you always" (176). There is no way of escaping a mechanical nonindividualized controlled body of yours; they are stuck in a body that cannot be privately or consciously controlled. The current technological and scientific contest for improving the natural body may be metaphorically extrapolated to the social entertainment force inherent in the novel.

\section{THEORY CONSTRUCTIONS OF THE EXTERNAL-BODY RELATION AND THE NEW HYBRID TECHNOLOGICAL INFLUENCED BODY}

Since entertainment poses a threat towards individual freedom and autonomy, characters no longer have control due to the generation of conducted repetitive processes. Infinite Jest creates excellent ripostes of separated body limbs and bodies working in an involuntary machine-like way. They become disembodied bodies due to social constructions. 
Piecing Together: Body Control, Mutability and Entertainment Technology in Infinite Jest

This perception is supported by Thomas J. Csordas in his Embodiment as a Paradigm of Anthropology, where he sees how body comportment is built into our bodies and thus it becomes an existential ground of culture. It is a recreation of the body which reinforces it as an unclear ground. This openness to social influence makes the body less stable. As Lyotard contends in "Anamnesis of the Visible, or Candour," before body is represented as a concept, as a "what," "there is no boundary to be crossed between an object and a subject existing in a mode of respective closure, but an instantaneous openness" (235). In Lyotard's words, it is more of an individual or body predisposition to be manipulated by the external rather than a firm borderline between both spaces (i.e. individual vs. social, external and social).

This idea additionally correlates to what Slavoj Žižek upholds, as for the latter cultural critic and philosopher this stance of body malleability is also only plausible if the individual allows it as such. He believes that the relation between the individual and the social is circular; one where the gap between the individual and the "impersonal" social dimension is to be inscribed back within the individual. This dimension of circularity is also highly implicit in the novel. As he states, "what [the individual and the social] share is the occurrence of an insurmountable parallax gap, the confrontation of two closely linked perspectives between which no neutral common ground is possible" (Parallax View 4).

However, this paper argues that the eternal fight is on the corporeality terrain. As the body is still an object where existential condition resides, it retains individuality which at some given point may collide with the social body. This reinforces the idea of the circularity of the representation of the body where both the social and the individual bounce against each other while at the same time chase each other. Hence, the body is increasingly seen as central to our sense of agency, but it can also still be a distinctive cultural artifact. And yet, it is the sense of control that has vanished which entails a discernible lack of dominion over their own body functions and parts. There is this rebounding feeling of body-ownership, "the perceptual status of one's body which makes bodily sensations seem unique to oneself, that is, the feeling that 'my body' belongs to me, and is ever present in my mental life" (Tsakiris 703). The body possesses the trait of being a subjected object as well as a determinate object due to disembodiment. Thus, it is the feeling of not possessing their own body or of carrying with them alien limbs 
as observed in the novel. Moreover, individuals are apparently receptive to the influence of the external, therefore they are in some way freed from their distinguishing cage of identity allowing comportment to be inscribed back into their bodies and thus encapsulating a socially determined body. N. Katherine Hayles installs this as part of the human into a "disembodied posthuman" (How We Became Posthuman 22). This kind of willingness of the body highlights the former as "an existential ground of culture" (Csordas 149), a hybrid of individual and social. However, although the self is culturally constituted there is an essential need for self-awareness for the sake of the working of society and as a general aspect of human personality configuration (Hallowell 1995). But in contrast to Irving Hallowell, who suggested that humans should recognize themselves as an object in the world of objects, MerleauPonty suggests that "it is false to place ourselves in society as an object among other objects, as it is to place society within ourselves in an object of thought" (Merleau-Ponty 421). It is what we may call a something in-between, a never-ending looping movement around the individual and the social. Moreover, Barthes also considers the body as the place for text description of society, but always due to its receptive nature. Therefore, by reasoning the former, it does not reject the idea of some kind of self-awareness, individuality or agency in the body. Due to the circularity dimension of individuals' position it shows how culture also springs from the body as culture does not only flow from the environment into the body but also emanates from the body into the environment. As Hayles states, "the body produces culture at the same time that culture produces the body" (How We Became Posthuman 200). Boundaries seem to be wracked in Infinite Jest, thus entailing the disappearance of dualisms. The dualism between matter and the external, the social and the individual all merge into one blurred object-subject parameter. This also parallels the layout of the narration in the novel as the novel advances and retreats at the same time. The story starts with the ending and all throughout the novel there is no logical or chronological constructions. Ironically, Joelle starts questioning this dualism:

what if hereditary, instead of linear, is branching? [...] What if in fact there were ever only like two really distinct individual people walking around back in history's mist? The whole and the partial. The damaged and the intact [...] The performer and the audience. (Wallace 220) 
Piecing Together: Body Control, Mutability and Entertainment Technology in Infinite Jest

But it is not until her last words that we come to realize that it is the same reality, "one upside-down in a convex lens" (220). This reference is parallel with tennis players and cartridge viewers who become deformed performers and attached elements of entertainment while they indulge entertainment in the same context reality.

As discussed, bodies seemed to have lost to a great extent their subjectivity and 'naturalness' entailing a new form, an "inhuman' [or subhuman] dimension" that Žižek contrasts to

not human" [that] means simply that he is external to humanity, animal or divine, while "he is inhuman" means something completely different: the fact that he is neither human nor inhuman, but marked by a terrifying excess which, although it negates what we understand as "humanity", is inherent to being-human. (Parallax View 22)

Bodies become text inscriptions of culture, receptive surface, and ground of social artifact and experience together with some existential condition. Body representation has conspicuously been part of the cultural domain in previous theories. By defining it as culturally driven, it directly adds to this, the connotation of unstable and multiple. Body then is represented as a map to be signified upon. However, a cultural offspring, technology, has taken over the whole (that is, over the cultural) and has gained a major role in body representation.

The shift from body as a blend of nature and spirit to a cultural-technological based body has put the focus on a rather external unstable set of representations. Thus, the question arises whether the body is objective or subjective, whether it exists within or without the physical parameters or it goes beyond. Through science and technology, the body has become a not truly self-unified and natural identity but connected parts that can be separated and revamped with some affinity or bond. This becomes an irreversible symbiosis where the body still retains some biological trace but it is the domain of an external force (in this case, technology). Therefore, under its reconfiguration the corporeality is swayed into unrecognizable authenticity of ownership. Moreover, if we are heading towards an irreversible symbiosis this implies the loss as 
well as the gain of traits. In this case, the loss of the natural body gives way to the gain and enhancement of its technological production and outcome.

In light of its machine-like attributes, the body appears to have become freed from its "selfish genes" (Žižek, In Defense 435), a situation that, according to Žižek is what occurs from the arising of the biotechnological and scientific paradigms. The naturalness of the body is distanced from the body whereby it creates a "new greater one," what he calls the " $2^{\text {nd }}$ nature" or "Life 2.0" (435), which is also observed in Infinite Jest. By heeding to the exaltation of a 2.0 or a Second Nature, it implies that there is no way back to the original but towards an accentuation of technological improvements applied to previous and old forms as a bridge towards enhanced malleable and machine-like bodies. In fact, technology is the one who has control over body-ownership. Moreover, in the novel the physical reality presents in an undefined loop of continual enhancing where bodies cannot return to their previous state or achieve the dubious ideal body site. They are clearly biological commodities stuck in a circular aimless drill. This leaves the body in a malleable state where the remaining "naturalness" and ownership is worked on as a means for technology exploration. Bodies are sublimated to technology as the key target of the corporeal experience. Consequently, this causes a false impression of autonomy although characters first need to willingly free their body members to the wheel of technology.

Hayles also states that "the place where we are is the place where nature is not" ("The Illusion of Autonomy" 675). But a hybrid link may reflect better the present status of the ever-emerging body. In the novel, Jim Incandenza's father breaks the boundary between natural bodies and technological creations by defining a car as if it were a body. He explains how machines and people are nonautonomous. He compares his car, which he considers to be a "lady," to a body that needs to be fueled by the external:

It will do what it's made for and do it perfectly, but only when stimulated by someone who's made it his business to know its tricks and seams, as a body [...] It's a body and will respond [...] that driver who treats its body like his own, who feels the big steel body he's inside, who quietly and unnoticed feels the nubbly plastic of the grip [...] just as he feels the skin and flesh, the muscle and sinew and bone wrapped in gray spiderwebs of nerves in the blood-fled hand just as he feels the plastic and metal and flange and teeth, the 
Piecing Together: Body Control, Mutability and Entertainment Technology in Infinite Jest

pistons and rubber and rods of the amber-fueled Montclair, when shifts. The bodily red of a well-nit lip, parping along [...] a toast to our knowledge of bodies. To high-level tennis on the road of life. (Wallace 159)

Jim Incandenza's father warns him about what seems to be affecting individuals and their bodies in the novel. "You are a machine a body an object, Jim, no less than this rutilant Montclair" (159). It is Life 2.0 which does not recall previous bodies but fills it with external strengthening support. It is not only this malleability but the body being a standing reserve, an object for technology. It is in some way a reprogramming of what body means.

There are characters in Infinite Jest who are more or less aware of this corporeality changing trait. One instance is when Jim's father is rambling about Marlon Brando, who needs to be fueled by external elements. It is the external objects that make him who he is and his body: "Marlon Brando felt himself as body so keenly he'd no need for manner $[. .$.$] he actually really touched whatever he touched$ as if it were part of him. Of his own body. The world he only seemed to manhandle was for him sentient, feeling" (158). He is part of the entertainment world and has a great cultural significance as an actor who Jim's mother is in love with.

Technology attempts body destruction, as we know it in its natural physicality. In the novel, technology in its many different forms attempts to reconfigure what we know as body boundaries and ownership. Technology is explored in the novel not only as enhancements attached to the body but also in its connection to mass media entertainment and drugs. These technological offshoots of entertainment seem to attain a major role in the life of the characters. They are driven by a compulsive machine-like quest for entertainment as well as falling into the wheel of collective entertainment. On the mainstream path to reach community entertainment, bodies are molded by the external technological force.

Drugs, sports or secret cartridges force characters to lose some of their humanistic features and they are all linked to the technology of entertainment. Therefore, this external "whimsical" factor to some extent forces representation of corporeality and hence, this element becomes a bodybuilder in the development of the novel. In the novel, Wallace highlights this irreversible symbiosis and malleability (sports, media and drugs) of the natural scope by 
heeding three major social groups connected to collective entertainment, tennis, cartridges and drugs. The latter, however, is only collective as the consequence of overuse of drugs as well as when they attempt to overcome addiction in a group such as Ennet Recovery House. He thoroughly and limitlessly relates to the repetitive and mechanical drills this group has to follow which the novel calls "autopilot ritual" (965). It is a manipulative stance but controlled by these bodybuilders. There is this sense of repetitive chaos where characters seem to be cooped up. Using Žižek's words, Wallace establishes that "the true catastrophe has already taken place [as] we already experience ourselves as in principle manipulable" (In Defense 448) without any chance of retreating the effects. Characters are freely and unconsciously swallowed in this thought. To achieve this status, bodies are represented in the novel as machine-like bodies. This perception privileges the molding and inscription of the body to technological products by technological systems. Tennis players are drilled unceasingly to produce the best enhanced performance of entertainment. Within this process they lose not only agency but the naturalness of their body. The major social role of entertainment gives way to the formation of body puppets. Tennis players are aware that they have reached the highest degree of perfection but are still forced to be the gears for the entertainment machine. They are subjected bodies for a bigger social network of entertainment.

The body is socially constructed, a site for reproducing "pleasure, a body infinitely teachable and adaptable" (Siebers 742). A guest at a social gathering where Joelle attempts to commit suicide suggests that "this, this whole thing, what you and I are discoursing within, is a technologically constituted space" (Wallace 232). This person connects a moment of pleasure such as a party to the influence of technology. They become open systems in a mediacontrolled world, where the external exerts its influence upon them. The world that is described in Infinite Jest is a world where even publicity and brands signify upon the years. Years are established according to different products, therefore entertainment in a broader sense also controls bodies.

Wallace's clearest intention in the sections about the President of the U.S., Johnny Gentle and the great Viney and Veals advertising company (which controls the entertainment and media world in the novel) is to demonstrate how his cleaning obsession and his campaign supported by V\&Vs ironically deform the body. It 
Piecing Together: Body Control, Mutability and Entertainment Technology in Infinite Jest

is the power of entertainment that performs deviation on the body. Their major plan of stashing toxic waste in the so-called Concavity/Convexity area has the side-effect of disfiguring corporeality. It metaphorically represents the waste entertainment produces on citizens. The appearance of "soft-skulled and extra-eyed newborns in the toxically affected area far exceeds the national average" (399), hinting at the major cause of the portrayal of distorted body representations. There are clear examples and factors that prove that President Johnny Gentle's plan is behind the "multieyed infant crawling backwards, its ear to the carpet, dragging its shapeless head like a sack of spuds" (401).

When it comes to tennis matches and training, the machinelike reproduction of "the same motions over and over, for decades" (110) transforms players' performance into sheer mechanical entertainment; defined as "a loop, it's hypnotizing" (110), which again points at the circularity implicit in the novel. Enfield's program (rolled out by the Head of the Tennis Academy Charles Tavis after Jim Incandenza's death and Gerhardt Schtitt, E.T.A.'s Head Coach and Athletic Director) "is supposedly a progression toward selfforgetting" (635). Young tennis players' natural body actions are suppressed, as Tavis and Schtitt discuss how the idea of sex is removed from the tennis players' minds. The self has no agency in body functions and its evolving in society.

\section{CONCLUDING NOTES}

This paper has offered an analysis of some major aspects unfolded by Wallace in Infinite Jest to demonstrate how the posthuman era has transformed what agency and body may entail by means of entertainment technology. Primarily, the findings have been subjected to critical theory and neuropsychological discoveries to demonstrate how monstrosity, machine-like or malleable representation in Infinite Jest are a symbolic device to identify the body-mind state and the dangers of the use and control of entertainment over body-ownership and thus, agency. This analysis confirms that Wallace manages to convey a sense of detachment of the body from the subjection of the self through the portrayal of these particular bodies. This is concordant with contemporary studies on body and critical theory on identity (Harraway, Hayles, Zizek, among others) that have proved to be advantageous for exploring the novel and the direction in which contemporary society 
is moving, whilst alerting against an incorrect and uncritical use of entertainment.

Wallace masterfully directs readers' attention towards mutable, disassembled bodies that represent the effects of entertainment technology and effectively, external control over the natural body. He does it in a way that depicts how entertainment objectifies bodies to the extent of losing the self towards new malleable and "enhanced" body parts. In this process, body parts that are not to be exploited are cast aside as part of the waste that entertainment produces. The result of this work highlights how Wallace invents images of separable, detached, monstrous corporeality that invite the reader to reflect upon the whirlpool of contemporary critical theories of body and identity embraced in the frame of entertainment technology.

\section{WORKS CITED}

BOURDIEU, Pierre. The Logic of Practice. Sanford University Press, 1990.

COUZENS, David Hoy. "Critical Resistance: Foucault and Bourdieu." Perspectives on Embodiment: Intersections of Nature and Culture, edited by Gail Weiss and Honi Fern Haber, Routledge, 1999, pp. 322 .

CSORDAS, Thomas J. "Embodiment as a Paradigm for Anthropology." Ethos, vol. 18 , no. 1,1999 , pp. 5-47.

DELEUZE, Giles and Félix Guattari. A Thousand Plateaus: Capitalism and Schizophrenia. Translated by Brian Massumi, Continuum, 2004.

FOUCAULT, Michel. Discipline and Punish: The Birth of Prison. Translated by Alan Sheridan, Random House, 1995.

---. "Nietzsche, Genealogy and History." The Foucault Reader, edited by Paul Rabinow, Pantheon, 1984, pp. 76-100.

FREUDENTHAL, Elizabeth. "Anti-interiority: Compulsiveness, Objectification, and Identity in Infinite Jest." New Literary History, vol. 41 , no. 1,2010 , pp. 191-211.

HALLOWELL, A. Irving. "The Self in Its Behavioral Environment." Culture and Experience, University of Pennsylvania Press, 1995, pp. 75-1. 
Piecing Together: Body Control, Mutability and Entertainment Technology in Infinite Jest

HARAWAY, Donna J. Simians, Cyborgs, and Women: The Reinvention of Nature. Routledge, 1991.

HASSAN, Ihab. "Toward a Concept of Postmodernism." Postmodernism: A Reader, edited by Thomas Docherty, Harvester Wheatsheaf, 1993, pp. 146-156.

HAYLES, Katherine N. How we Became Posthuman. University of Chicago Press, 1999.

---. "The Illusion of Autonomy and the Fact of Recursivity: Virtual Ecologies, Entertainment, and Infinite Jest." New Literary History, vol. 30, no. 3, 1999, pp. 657-697.

JAMESON, Fredric. Postmodernism, or, the Cultural Logic of Late Capitalism. Duke University Press, 1991.

---. "Postmodernism and the Consumer Society." Postmodern Culture, edited by Hal Foster. Pluto Press, 1985, pp. 111-125.

LICKLIDER, Joseph C.R. "Man-Computer Symbiosis." IRE Transactions on Human Factors in Electronics, vol. 1, 1960, pp. 4-11.

LONGO, Matthew R., and Patrick Haggard. "A 2.5D Representation of the Human Mind." Journal of Experimental Psychology: Human Perception and Performance, vol. 38, no. 1, 2010, pp. 9-13.

LYOTARD, Jean-Francois, "Anamnesis of the Visible, or Candour." The Lyotard Reader, edited by Andrew Benjamin, Blackwell, 1989.

MERLEAU-PONTY, Maurice. The Phenomenology of Perception. Translated by Colin Smith. Routledge, 1962.

PORUSH, David. The Soft Machine: Cybernetic Fiction. Methuen Young Books, 1984.

RUSSELL, Emily. "Some Assembly Required: The Embodied Politics of Infinite Jest." Arizona Quarterly: A Journal of American Literature, Culture, and Theory, vol. 66, no. 3, 2010, pp. 147-169.

SIEBERS, Tom. "Disability in Theory: From Social Constructionism to the New Realism of the Body." American Literary History, vol. 13, no. 4, 2000, pp. 737-754. 
TSAKIRIS, Manos. "My Body in the Brain: A Neurocognitive Model of BodyOwnership." Neuropsychologia, vol.48, no. 3, 2010, pp. 703 -712.

WALLACE, David Foster. Infinite Jest. Back Bay Books, 2006. 